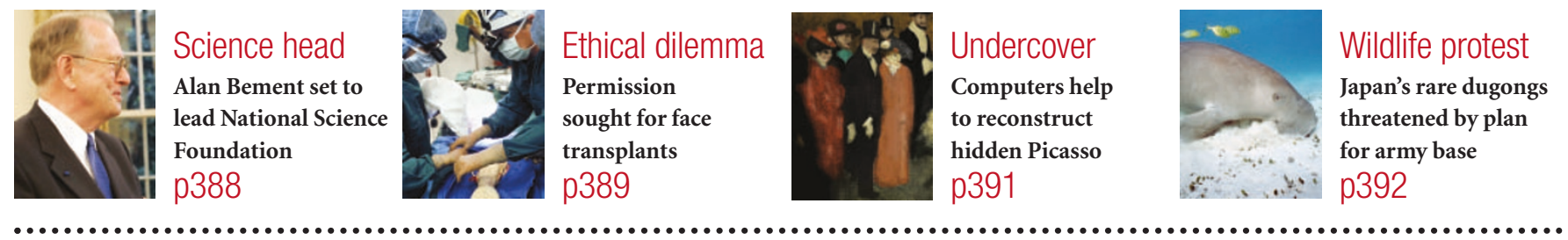

\title{
European space scientists brim with ideas for going it alone
}

\section{Quirin Schiermeier, Munich}

Europe's top space researchers are calling on the European Space Agency (ESA) to develop a bolder vision for space research and exploration.

At a meeting held in Paris last week, researchers said that they wanted the agency to develop a scientific profile that would be more distinct from that of NASA, the agency's US counterpart. Many urged ESA to embrace space-based experiments in particle physics and the search for extraterrestrial life, in addition to its traditional priorities of astronomy and planetary exploration.

Some 400 researchers, including most of Europe's leading space scientists, attended the Cosmic Vision 2015-2025 meeting. Such meetings are held every ten years to collect ideas for ESA's science plan, the next of which is scheduled to be published next year.

Some researchers at the meeting called on ESA to rethink its existing mix of collaboration and competition with NASA. Their doubts about the US agency's leadership have been fuelled by uncertainty about the International Space Station, confusion over NASA's plans to return to the Moon and to Mars, and the agency's propensity to hog the limelight for results obtained from joint projects.

European planetary scientists are especially keen to break free from NASA's influence. "We shouldn't be deterred by what NASA plans to do," says Wolfgang Baumjohann, director of the Space Research Institute in Graz, Austria, who chairs ESA's working group on Solar System science. "We want to go outward ourselves and explore the Solar System beyond Jupiter and its satellites - and we also want to land on moons and planets, and return samples."

Researchers are particularly keen to explore Europa, one of Jupiter's moons, which is thought to harbour a vast lake beneath a thick crust of ice. NASA has already proposed a similar mission, the Jupiter Icy Moons Orbiter. This revolutionary spacecraft - part of the US agency's Project Prometheus - would be powered by nuclear fission. But doubts have been expressed over the mission's feasibility (see Nature 431, 113; 2004). European scientists are hoping that

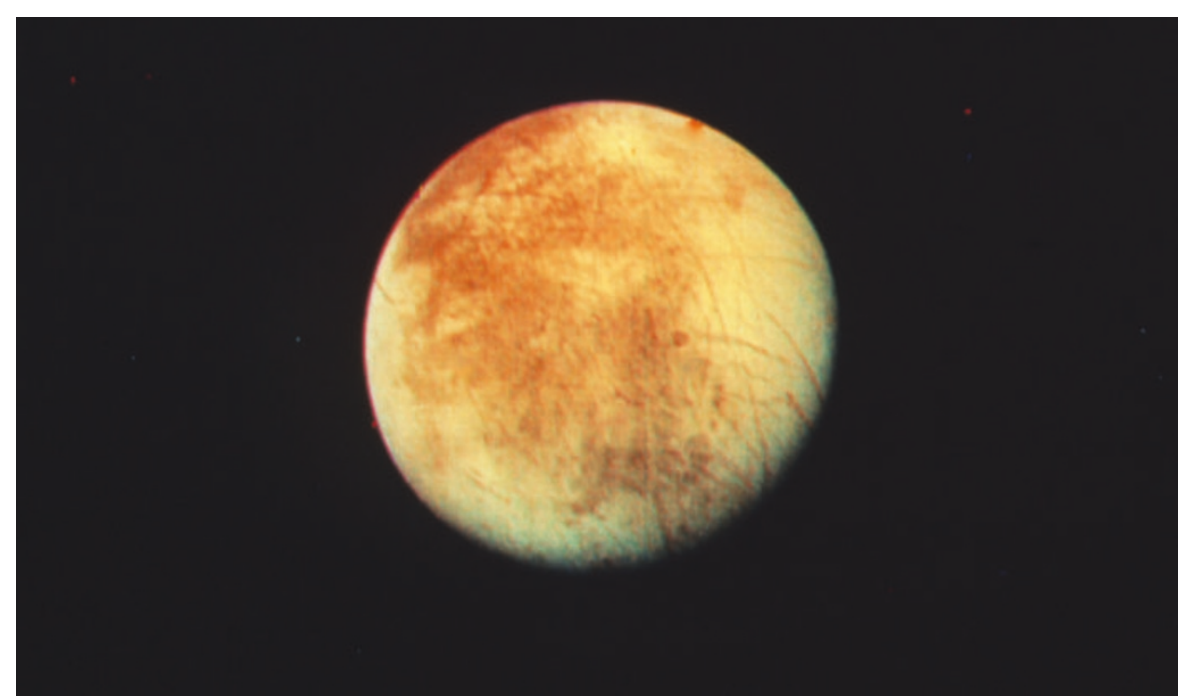

Higher profile: European scientists want to mount a solo mission to Europa.

ESA will back a cheaper and less technically challenging Europa mission, fuelled by conventional power sources.

European physicists, meanwhile, would like to build space-based experiments, says Bernard Schutz, a director at the Max Planck Institute for Gravitational Physics near Potsdam, Germany, and chair of ESA's fundamental physics advisory group.

For example, researchers would like to use an array of spacecraft, communicating with each other by laser, to detect gravitational waves - faint disturbances in the curvature of space-time predicted by Albert Einstein. By monitoring the distances between the spacecraft, scientists hope to detect the mysterious ripples, which are thought to emanate from major cosmological events such as collisions between black holes, as well as from the Big Bang. In addition, space-based quantum experiments are being designed to measure phenomena such as possible slow variations in fundamental physical constants over time.

"These things need to be explored in space," says Schutz. "We just can't make lab experiments last long enough to gain any clarity."

Competition between the United States and Europe is also driving the search for habitable planets outside the Solar System. European scientists hope that advanced observation tools will allow them to detect biomarkers in the atmosphere of planets around distant stars, says Catherine Turon, an astronomer at the Paris Observatory at Meudon.

At the meeting, researchers presented 150 different ideas that will now be considered in more detail by ESA advisory committees for possible inclusion in next year's plan. The meeting drew twice as many proposals as the previous one in 1994.

"I am delighted about the number and quality of the ideas brought forward," says Giovanni Bignami, chairman of ESA's space science advisory committee. "But it is obvious that we still have too much vision for even the most rosy predictions of budget increases."

From its total annual budget of $€ 2.7$ billion (US\$3.3 billion), ESA currently spends $€ 370$ million per year on science an order of magnitude less than NASA, although the European agency's money goes a long way because most researchers' salaries are paid by their home nations. In the next six months, ESA's advisory groups will analyse and revise the proposals to a reasonable size, so that they will fit in with the agency's limited resources. 